\title{
Performance in the Stroop Color Word Test in relationship to the persistence of symptoms following mild head injury
}

Citation for published version (APA):

Bohnen, N., Twijnstra, A., \& Jolles, J. (1992). Performance in the Stroop Color Word Test in relationship to the persistence of symptoms following mild head injury. Acta Psychiatrica Scandinavica, 85(2), $116-121$. https://doi.org/10.1111/j.1600-0404.1992.tb04009.x

Document status and date:

Published: 01/01/1992

DOI:

10.1111/j.1600-0404.1992.tb04009.x

Document Version:

Publisher's PDF, also known as Version of record

Please check the document version of this publication:

- A submitted manuscript is the version of the article upon submission and before peer-review. There can be important differences between the submitted version and the official published version of record.

People interested in the research are advised to contact the author for the final version of the publication, or visit the DOI to the publisher's website.

- The final author version and the galley proof are versions of the publication after peer review.

- The final published version features the final layout of the paper including the volume, issue and page numbers.

Link to publication

\footnotetext{
General rights rights.

- You may freely distribute the URL identifying the publication in the public portal. please follow below link for the End User Agreement:

www.umlib.nl/taverne-license

Take down policy

If you believe that this document breaches copyright please contact us at:

repository@maastrichtuniversity.nl

providing details and we will investigate your claim.
}

Copyright and moral rights for the publications made accessible in the public portal are retained by the authors and/or other copyright owners and it is a condition of accessing publications that users recognise and abide by the legal requirements associated with these

- Users may download and print one copy of any publication from the public portal for the purpose of private study or research.

- You may not further distribute the material or use it for any profit-making activity or commercial gain

If the publication is distributed under the terms of Article 25fa of the Dutch Copyright Act, indicated by the "Taverne" license above, 


\section{Performance in the Stroop color word test in relationship to the persistence of symptoms following mild head injury}

\author{
Bohnen N, Twijnstra A, Jolles J. Performance in the Stroop color word \\ test in relationship to the persistence of symptoms following mild head injury. \\ Acta Neurol Scand 1992:85: 116-121 \\ There is much controversy about whether the persistence of postconcussive \\ symptoms (PCS) in mild head injured patients (MHI) is related to the \\ presence of cognitive deficits. Most studies performed so far have relied on \\ normal non-concussed control subjects rather than directly comparing \\ patients with and without PCS following MHI. In addition, subtle cognitive \\ deficits may be present in MHI patients that are demonstrable only with \\ more demanding cognitive tasks. In the present study the Stroop Color Word \\ Interference Test logether with a more demanding modified interference \\ subtask was administered to two groups of patients with uncomplicated MHI \\ 10 days, 5 weeks and 3 months after the injury. Ten patients with \\ persistent symptoms at 3 months were selected and individually matched. \\ with MHI patients who had initially reported symptoms but who had \\ recovered by 3 months. The scores of the two retrospectively defined groups \\ were compared at the different time points. Between-subjects analysis \\ revealed overall differences for both the original and modified color word \\ interference subtask. Within-subject analysis indicated that only the recovery \\ rate in the modified interference subtask was significantly different \\ between the two groups. The observation that there was a parallel trend \\ between recovery and persistence of PCS and performance on the cognitive \\ interference moastres supports the notion that there is a functional \\ relationship between these two phenomenat
}

\author{
N. Bohnen ", A. Twijnstra ${ }^{2}$, J. Jolles" \\ Departments of "Neuropsychology \& \\ Psychobiology, University of Limburg. \\ ${ }^{2}$ Neurology, University Hospital Maasinicht, \\ The Netherlands
}

Key words: attention; mild head injury; Stroop color word test

N. Bohmen, Department of Neuropsychology \& Psychobiology, Uniwersity of Limburg, P.O. Box $616,6200 \mathrm{MD}$ Maastricht. The Netherlands

Accepted for publication August 5, 1991
Studies of patients with mild head injury (MHI) cover a heterogeneous population as there are subgroups of patients who recover quickly, within days, whereas others have persistent postconcussive symptoms (PCS) after the first weeks of recovery. Estimates of the incidence of PCS in the first months following MHI vary from $20-80 \%$ (review 1). Evidence is accumulating that even mild to moderate head injury may produce subtle cognitive deficits $(2,3)$. These deficits appear to selectively impair functions of altention and information processing and are found most consistently with more complex and demanding tasks (4). Gronwall \& Wrightson (5) reported that functions of information processing were impaired during the first weeks post injury, with resolution by 35 days unless posttraumatic symptoms persisted. These authors suggested that a reduction in the rate of information processing was an important factor in the genesis of the postconcussion syndrome. In addition, Jakobsen et al. (3) were able to predict the persistence of PCS by using a reaction time task. In contrast, there are other reports that do not support a relationship between the presence of postconcussive sequelae and reaction time measures (2) or memory deficits (6). These conflicting results may be because of methodological differences, such as the heterogenticity of the patient groups, the different post-injury time intervals, the nature of the cognitive test used, and the extent of everyday stress the cognitively disturbed patient experiences.

The Stroop color word test (7) has been used as a test to measure selective attention in head-injured patients (8). Although there are several versions of the Stroop test, the essence of the interference subtask is that the subject has to name a set of colors when they are printed as letters in ink of a conflicting color (e.g., "blue" printed in green ink). Generally, the difference in time taken by subjects to perform the interference subtask compared with the subtasks of color naming or reading is thought to be because the automatic reading response interferes with the response required by the task; thus the time taken can be considered a measure of selective attention $(9,10)$. So far, studies that have used the Stroop 
color word test with moderately to severely headinjured patients have yielded consistent results and indicate that head-injured patients are slower than controls in both the color naming, and color naming with interference tasks, but that they are not disproportionately slower in the interference test when data are aggregated at a group level $(11-14)$. As there are patients who recover completely within days or weeks after MHI (5), it is evident that there are different subgroups within a general population of patients with $\mathrm{MHI}$, varying from subjects with no or only minimal brain damage to patients with more severe posttraumatic brain dysfunction. Therefore, it was the first aim of the present study to investigate the recovery of different, retrospectively defined, subgroups of patients with $\mathrm{MHI}$ with and without PCS by using the Stroop color word test. The second aim of the study was to determine whether a more demanding, modified color word interference task that has face validity with situations which require flexibility in the planning and execution of complex behavioral acts - could increase the sensitivity of the Stroop test to detect posttraumatic brain dysfunction.

The demands of the newly developed subtest compared with the orthodox color word interference subtask are greater, as flexibility is required to shift between the naming and reading of the items depending on a special visual cue given with the words. Recently, we found that an unselected group of patients with MHI performed on this modified interference subtask less well than non-concussed subjects, in contrast to their performance on the orthodox interference subtask (unpublished data).

We used patients who were recovering from $\mathrm{MHI}$ as controls to better isolate the experimental variable of recovery in order to test the hypothesis that the presence or absence of subjective recovery from head injury affected performance on the cognitive measure.

\section{Subjects and methods}

Two groups of MHI patients were selected from a larger population of patients ( $N=43: 22$ women, 21 men, mean age $27.7 \pm 13.1 \mathrm{yr}: \mathrm{SD}$ ) who were participants in a comprehensive cohort study of patients with uncomplicated MHI. The frst group (Group A) consisted of 10 ( 5 women, 5 men) who still complained of persistent PCS 3 months after the trauma. In contrast, Group B consisted of carefully matched patients who initially reported $\mathrm{PCS}$, but gradually improved and had completely recovered 3 months after the injury. Patients were individually matched for age ( \pm 4 years; range), sex and educational level $( \pm 1$ level; range) $(15)$.

The criteria for inclusion in the larger MHI study included a posttranmatic amnesia not exceeding $60 \mathrm{~min}$, a period of unconsciousness of less than 15 min, a Glasgow conna score of 15 on admission, no serious traumatic physical complication (including the absence of an orthopaedic injury), and willingness to participate. Patients who had been intoxicated at the time of the trauma, had a skull fracture, had evidence of a neuropsychiatric history or had sustained a head injury within the last 10 years were excluded. No subjects were involved in litigation. Follow-up assessments took place 10 days $(6-14 \mathrm{~d})$, 5 weeks (4-6w), and 3 months (12-16 w) after the injury. All patients and controls were younger than 45 years. None of the subjects were color blind. The mean age and educational level of the subjects are presented in Table 1 . With respect to the severity of the mild head injury there was no significant difference between the two groups when patients were categorized according to the duration of the posttraumatic amnesia (PTA shorter or longer than $15 \mathrm{~min})$. There were three patients with a PTA longer than 15 min in Group $A$, whereas there were four in Group $B(P>0.05)$. All subjects gave their informed consent.

\section{Postconcussive symptoms}

A checklist of postconcussive symptoms was completed, which included items such as headache, dizziness, nausea, irritability, difficulties with concentration and memory, fatigue, sleep disturbances and blurred vision. As these symptoms can also occur in non-concussed subjects (16), the symptoms were scored for their absolutely or relatively increased appearance after the injury in comparison with the pretraumatic condition.

All the patients with persistent PCS (Group A) complained of several PCS up to 3 months after the injury without there being significant recovery. In contrast, the patients of Group B initially complained of PCS at 10 days and 5 weeks but had completely recovered by 3 months (Table 2 )

\section{Test material}

Stroop test - The Stroop color word interference test used in the present study is a commercial version available in the Netherlands (Swets \& Zeitlinger, Lisse, 1971). The test consists of three parts, with

Table 1. Age and educational level (15) of patients with (PCS+) and withoul (PCS-) persistent symptoms 3 months after MHI. Mean data are presented ( \pm SO)

\begin{tabular}{lcc}
\hline & Age & Eviucational tevel \\
\hline PCSt & $25.0+9.7$ & $4.7 \pm 0.67$ \\
PCS- & $24.8 \pm 9.73$ & $4.6 \pm 0.72$ \\
\hline
\end{tabular}




\section{Bohnen et al.}

Table 2. Frequency distributhon of postconcissive symptons tor the two groups at the three follow-tp assessnents labsolute numbers. PCS t patuents with persistent PCS 3 months lollowing MHI $N=101.9 C S-p a t i e n s$ wha higd subjectively recovered by 3 monthis $\langle N=10$

\begin{tabular}{|c|c|c|c|c|c|c|}
\hline & \multicolumn{2}{|c|}{10 days } & \multicolumn{2}{|c|}{5 weeks } & \multicolumn{2}{|c|}{3 months } \\
\hline & PCS- & PCSt & $\operatorname{PCS}-$ & PCS4 & PCS - & PCSt \\
\hline Heardache & 7 & $B$ & 6 & 7 & 0 & 9 \\
\hline Mausea & 0 & 2 & 0 & 1 & 0 & 1 \\
\hline Fatigue & 8 & 10 & 7 & 9 & 0 & 9 \\
\hline Dizziness & 9 & $B$ & 4 & $\hat{6}$ & 0 & 6 \\
\hline Forgetul & 5 & 8 & 2 & 6 & 0 & 7 \\
\hline Poor concentration & 7 & 7 & 4 & 6 & 0 & 8 \\
\hline Disturbed sleep & 6 & 6 & 5 & $B$ & 0 & 7 \\
\hline Blurved vision & 10 & $B$ & 1 & 0 & 0 & 0 \\
\hline \multicolumn{7}{|l|}{ At least } \\
\hline 1 PCS & 10 & 10 & 6 & 10 & 0 & 10 \\
\hline \multicolumn{7}{|l|}{ More than } \\
\hline 3 PCS or more & 8 & 10 & 4 & 8 & 0 & $g$ \\
\hline
\end{tabular}

each part being presented on a $21 \times 29.5 \mathrm{~cm}$ sheet of paper. Ten lines are printed in each subtask with 10 items per line. The test examines the speed at which 100 color names (yellow, green, red, and blue) are read (subtask 1) and the speed at which 100 colored spots are named (subtask 2). Subtask 3 again involves 100 color names, but the naming of the printing ink of the words is taken as the test variable. The color word interference measure is obtained by subtraction of the time needed for subtask 2 from that needed for subtask $3(3-2)$.

New subtask 4 - Twenty words from subtask 3 were randomly selected, and 20 small rectangles $(0.8 *$ $2.0 \mathrm{~cm}$ ) were drawn around these words (Fig. 1). The instructions as given to subjects for the modified subtask (subtask "4") were the same as these for subtask 3, except for the rectangularly lined items. For these items the subject was requested to read the printed word.

A component of subtask 1 (reading names) constituted $20 \%$ of the trials of subtask 4 . Therefore, subtraction of the time of a weighted combination of the times needed for subtasks 1 and $2[1 / 5 * t$ (subtask 1) $+4 / 5 * t($ subtask 2$) ; t=$ time in seconds] from the time needed for subtask 4 was calculated as the interference measure for subtask 4 . All subjects were instructed to perform the task as quickly and as accurately as possible. Further details about the subtask will be described elsewhere.

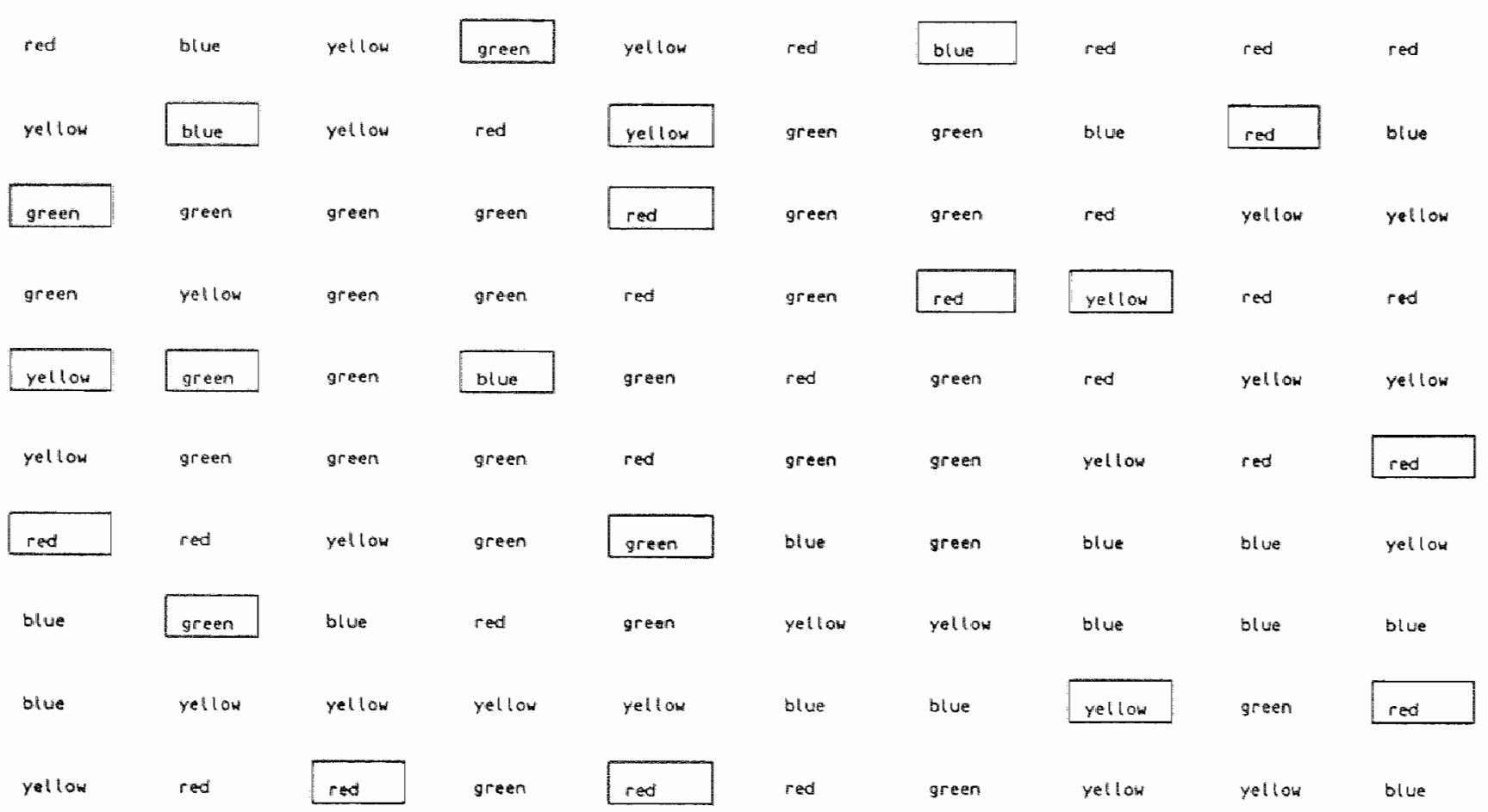

Fig. 1. Modified subtask of the Stroop collor word interterence test: 20 items were randomly placed within a rectangle. 
Analysis

Data were analyzed by using an analysis of variance with the factor "group" (patients with and without PCS at 3 months) and the factor "time" (10 days, 5 weeks and 3 months) with repeated measures on the last factor (17). Within-subjects analysis was applied to assess differences in the recovery rates for each subtask. Between-subjects analysis was used to evaluate overall differences between groups per subtask. Univariate tests per time point were applied for significant main effects. In addition, the interference measures of the two subtasks were analyzed when the raw scores of the subtasks were significantly different. Probabilities greater than 0.05 were considered as nonsignificant.

\section{Results}

The results for the four subtasks of the Stroop test for the two patient groups at the different times are presented in Table 3. Repeated measures ANOVA revealed no significant time* group interaction or an overall "group" effect for either subtask 1. $[\mathrm{F}(2,36)=1.23$, ns and $\mathrm{F}(1,18)=1.41$, ns, respectively] or subtask $2 \quad[\mathrm{~F}(2,36)<1$, ns and $\mathrm{F}(1,18)=2.08$, ns, respectively]. Although the time *group interaction term for subtask 3 was not statistically significant $[\mathrm{F}(2,36)=2.85, \mathrm{P}=0.08]$, there was a significant overall "group" effect on this subtask $[F(1,18)=6.82, P<0.01]$. The two groups differed both at 5 weeks $[F(1,18)=5.40, P<0.05]$ and 3 months $[F(1,18)=8.56, P<0.01]$ on this measure.

There was a significant time*group interaction $[F(2,36)=8.76, P<0.01]$ and an overall "group"

Table 3. Results of the Stroop color word interference test. Means (seconds) are presented with SD. PCS + patients with persistent PCS 3 months following MHII, PCSpatients who had subjectively recovered by 3 months. Significant differences between the two groups are marked with asterisks

\begin{tabular}{lccc}
\hline & 10 days & 5 weeks & 3 months \\
\hline $\begin{array}{l}\text { Subtask 1 } \\
\text { PCSt }\end{array}$ & $49.02(11.67)$ & $47.64(13.10)$ & $47.96(12.86)$ \\
PCS- & $41.64(4.06)$ & $40.59(4.20)$ & $39.54(4.89)$ \\
Subtask 2 & & & \\
PCSt & $62.97(13.89 *$ & $58.72(15.75)$ & $61.12(6.91)$ \\
PCS- & $52.25(6.12)$ & $48.88(6.13)$ & $50.04(5.67)$ \\
Sublask. & & & \\
PCSt & $93.97(17.48)$ & $90.33(17.48)^{*}$ & $94.49(24.39)^{* *}$ \\
PCS- & $80.30(13.05)$ & $72.69(16.16)$ & $68.81(13.26)$ \\
Subtask 4 & & & \\
PCSt & $106.79(19.77)$ & $101.96(23.50 *$ & $101.60(22.26)^{* * *}$ \\
PCS- & $97.15(19.58)$ & $82.44(12.88)$ & $75.12(12.41)$ \\
\hline
\end{tabular}

* $P<0.05$.

* $P<0.01$. effect $[F(1,18)=4.49, P<0.05]$ for the scores of the modified subtask 4 . Further analysis per time point indicated that the groups did not differ at 10 days, but were significantly different at 5 weeks $[\mathrm{F}(1,18)=5.31, \mathrm{P}<0.05]$ and at 3 months $[F(1,18)=10.55, P<0.01]$ (Fig. 2).

Because of the significant differences between the raw scores of subtask $3 \& 4$ at 5 weeks and 3 months, the two interference measures were compared between the two groups: there were only significant differences at 3 months. For the interference derived from subtask $3(3-2)$ PCS patients scored $33.37 \pm 15.07$ versus patients without PCS $18.76 \pm 11.03,[\mathrm{~F}(1,18)=6.07, \mathrm{P}<0.05]$. For the interference measure derived from subtask 4 the mean scores for the patients with PCS were 46.01 \pm 15.77 , and for the patients without PCS 27.18 \pm 9.95 , $[F(1,18)=9.91, P<0.01]$. This indicates that the patients with PCS were disproportionately slower at the two interference measures only 3 months after injury in comparison with the patients who had recovered by 3 months.

\section{Discussion}

Studies in which the Stroop color word test has been used with head-injured patients have yielded consistent results indicating that the patients have no specific difficulty in focusing on the color dimension of the ambiguous stimuli when data are aggregated at a group level $(11,14,18)$. In the present study, the MHI patients were divided into subgroups with respect to the persistence of symptons. We found that patients with persistent PCS at 3 months had more difficulties with the Stroop color word interference measure $(3-2)$, than patients without PCS but not at 10 days and 5 weeks when both groups consisted of patients who had persistent symptoms at these times. This interference effect at 3 months could not be explained by a slowness to name colors (subtask 2). Within-subject analysis indicated that only the recovery rate in the modified interference subtask was significantly different between the two groups. The extra flexibility in attentional demands and strategies needed in the modified subtask to direct attention to the different interference stimuli requires more effort from the patients with PCS than from the patients without PCS. This notion is consistent with circumstantial evidence that the cognitive deficits of MHI patients are especially manifested when cognitive demands are high and when patients have to deal with the complex tasks.

The present results are in accordance with the study of Gronwall (19) who found that the number and severity of PCS symptoms decreased as the rate of information processing improved. In contrast, Ruff et al. (6) found that recovery from memory 


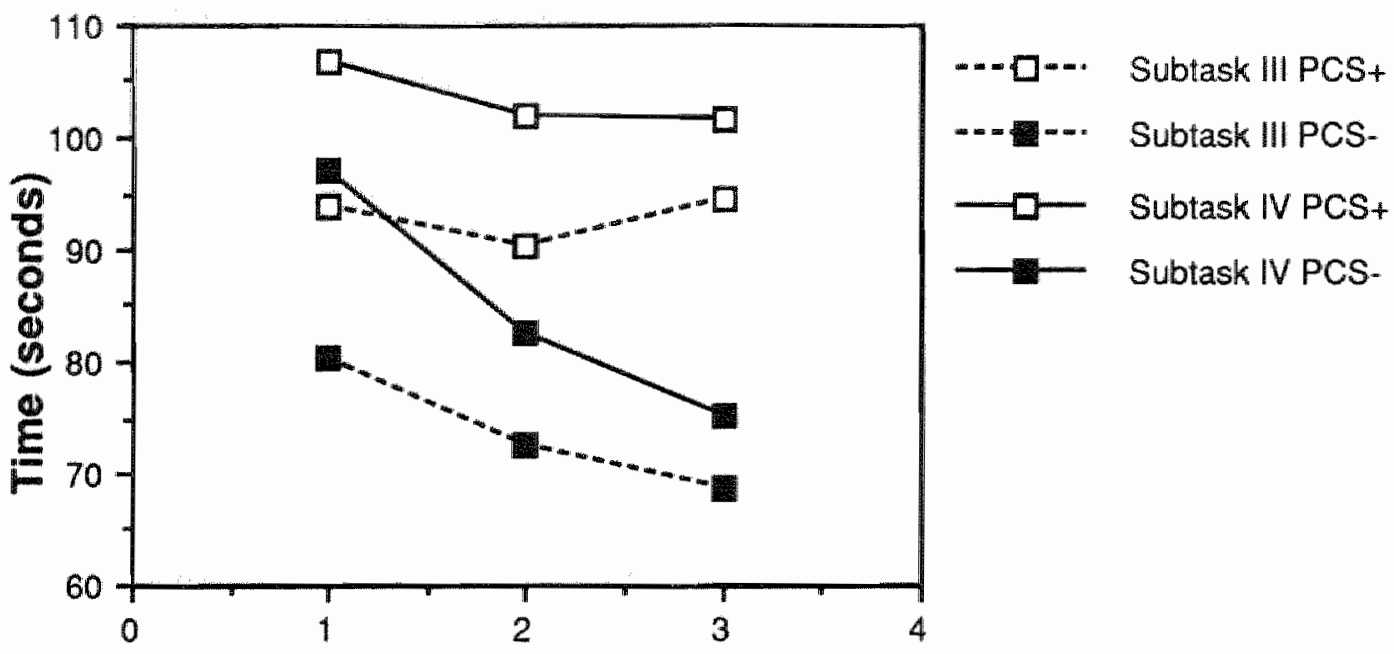

Assessment

Fig. 2. Mean scores at the Stroop color word interference subtask 3 and the modified more complex interference subtask 4 for patients with and without PCS 10 days $(=$ assessment 1 ), 5 weeks (=assessinent 2) and 3 months (= assessment 3 ) after the injury.

deficits following $\mathrm{MHI}$ did not parallel recovery from PCS. It is possible that persistence of PCS may be related more to disturbances in information processing than to changes in intrinsic memory functions.

As we have no data on the premorbid cognitive and personality functions of the patients, it is possible that these could be biasing factors. Nevertheless, only patients with uncomplicated MHI who did not have a premorbid compromising condition were selected. Patients were also matched for their educational level. Despite the persistence of symptoms, 9 of 10 patients had resumed their work within 3 months after the injury. It has been reported that cognitive performance can deteriorate over time in patients with high levels of stress and emotional repercussion after the injury (5). In the present study it appeared that in 4 patients with PCS the resumption of work aggravated both their symptoms and their cognitive performance (Tables 2, 3). This is consistent with circumstantial evidence that the appearance of PCS depends on the level of environmental stress that a patient has to cope with. From a reverse point of view, patients appear to be able to cope with the demands of everyday life only when no time pressure is laid upon them or when they are allowed to do one thing at the time in their own tempo.

Connor et al. (20) found a clear practice effect with repeated testing of the Stroop test in healthy subjects, especially from the first to the second testing. We found that healthy subjects also displayed a clear practice effect on repeated testing with the modified subtask (mean $-7.64 \%$ ). The mean percentage change in performance on the modified subtask between the first two assessments was $-4.6 \%$ for patients with persistent PCS and $-14.3 \%$ for the patients who had recovered. Although a direct comparison may not be valid (21), it appears that the improvement in the latter group is due to both recovery and practice effects.

It can be summarized that the persistence of PCS following uncomplicated MHI may be related to the persistence of a cognitive deficit as detected in a color word interference task. With respect to the recovery of symptoms of MHI, there was a significant relationship between subjective recovery and the recovery rate in the modified more complex subtask. Patients with PCS may have more difficulties with perceptually interfering stimuli than MHI patients without persistent PCS.

\section{Acknowledgement}

The authors express their gratitude to Mrs. Germa Wijnen for excellent assistance in performing the sudy.

\section{References}

1. RUTHERford WH. Postconcussion symptoms: relationship to acute neurological indices, individual differences and circumstances of injury. In: $\mathbb{L}$ EVIN HS, EISENBERG HM, BENTON AL eds. Mild head injury. New York: Oxford University Press, 1989: 217-228.

2. MacFlynn G, Montgomery EA, Fenton GW, RuthERFORD W. Measurement of reaction time following miror head injury. I Neurol Neurosurg Psychiatry 1984: 47: 13261331.

3. Jakobsen J, BaAdSGaAd SE. Thomsen S, Henriksen PB. Prediction of postconcussional sequelae by reaction time test. Acta Neurol Scand 1987: 75: 341-345.

4. Hugenholtz H, Stuss DT, StetheM BA. RiChard MT How long does it take to recover from a mild concussion? Neurosurgery 1988: 22: $853-858$ 
5. Gronwall D, Wrightson P. Deldyed recovery of intellectual function after minor head ingury. Lancet $1974: 2 ; 605-$ 609.

6. RUFF RM, LEWIN HS, MATTIS S et al. Recovery of memory after mild head injury: a three-center study. In: LEVIN HS, Eisenberg MM, Benton AL, eds. Mild head injury. New York: Oxford Uniwersity Press, 1989: 176-188.

7. STROOP JR. Studies of interference in serial werbal reactions. J Exp Psychol 1935: 18: 643-662.

8. VAN ZOMEREN AH, BroUwer WH. Head injury and concepts of altention. In: LEVIN HS, GrRAFMAN J, ETSENBera HM, eds. Neurobehavioral recovery from head injury. New York: Oxford University Press, 1987: 398-415.

9. DYER FN. The Stroop phenomenon and its use in the study of perceptual, cognitive and response processes. Memory Cognition 1973: 1: 106-120.

10. Lowe DG, Mitterer JO. Selective and divided attention in a Stroop task. Can J Psychol 1982: 36:684-700.

11. Chadwick O, Rutter M, Brown G, Shaffer D, Traub M. A prospective study of chidhen with head injury. II. Cognitive sequelae. Psychol Med 1981: 11:49-62.

12. MClean A, TEMKIN NR, DIKMEN S, WYLER AR. The behavioural sequelae of head injury. J Clin Neuropsychol 1983: 5: 361-376.

13. Stuss DT, ELY BA, Hugenholz H at all. Subte neuro- psychological deficits in patients with good recovery after closed head injury. Ncurosurgery 1985: $17,41-47$.

14. Thomas C. Deficits of memory and atention following closed head injury. Thesis: Oxford Universily, 1977.

15. VerHAGE R. Inteligentie en leenid. Thesis. Assen, The Netherlands, 1964.

16. DIKMEN S, MCLEAN A, Temkin N. Neuropsychological and psychosocial consequences of minor thead injury. I Nearol Neurosurg Psychiatry 1986: 49:1227-1232

17. SAS User's Guide: Statistics. North Carolina. Cary: SAS Institute, 1985.

18. ACKER MB, DAvis JR. Psychology test scores associated with late outcome in head injury. Neuropsycholog 1989: 3. $123-133$.

19. GRONWALE D. Performance changes during recovery from closed head injury. Proc Aust Assoe Neurol 1976: 13: 143147.

20. CONNOR A, FRANZEN M, SHARP B. Effects of practice and differential instructions on Stroop performance. In I Clin Neuropsychol 1988: 10:1-4.

21. DIKMEN S, TEMKIN N. Determination of the effects of head injury and recovery in behavional research. In: LEVIN HS, GrAFMAN J, EISENBERG HM, eds. Neurobehavional recovery from head injury. New York: Oxford University Press, 1987:73-87. 